\title{
Comunicaciones
}

\section{INTERPRETACIÓN Y MÉTODO en Carlo Ginzburg}

\author{
Jose OMAR ACHA
}

\section{La ontología histórica: cultura y conflicto}

Carlo Ginzburg publicó su primer libro en $1966 .^{(1)}$ Era una investigación sobre un núcleo de creencias populares de la campaña en el norte de Italia, en el Friuli. Ginzburg planteaba su indagación como la búsqueda de las raíces de la constitución de la brujería y de su persecución. Su hipótesis es que se trata de la conversión de un antiguo culto agrario en la brujería con prácticas sabáticas tales como la descripta en los textos inquisitoriales. Para ello utiliza una documentación única en su género: un conjunto de procesos inquisitoriales contra campesinos/as friulanos que permiten descubrir en un lapso de cincuenta años la persistencia de un culto agrario y su gradual transformación - para los mismos campesinos- en una secta brujesca. Para analizar la documentación que abarca muchos elementos, y para no caer en la mera descripción de rasgos pintorescos, Ginzburg apela al concepto de mentalidad colectiva, aunque lo abandonará pronto. En este abandono se juega más de lo que parece.

Ya en este texto, como lo repetirá con algunos matices en un libro más tardío, ${ }^{(2)}$ son postulados orígenes específicamente populares de la brujeria. Existiría un fondo de creencias populares, que no son reducibles a la imposición de mitos y saberes de los sectores cultos (y dominantes) de la sociedad. En cuanto objeto de investigación, podemos reconocer en esta cuestión el eje de la problemática que Ginzburg ha perseguido durante casi cuatro décadas: si lo que llama la cultura popular es una creación autónoma, o en todo caso si posee una lógica autónoma de desarrollo, o si es una imposición de las clases dominantes. Porque la postulación de que desde las prácticas, desde la experiencia, se podía crear un tipo de conocimiento ("indiciario") hace sistema con otra afirmación: que las clases subalternas no son idiotas, que resisten y resignifican las prácticas y discursos provenientes de las clases dominantes. Además de ello también las comunidades campesinas tenian sus propias tradiciones y creencias. Ginzburg siempre creyó, y trató de probar, que existía un sustrato de

* Universidad de Buenos Aires. 
creencias populares que datan de los tiempos remotos, y que son una herencia actualizada que no es eliminada por el dominio y la coerción a que aquellas comunidades fueron sometidas. La interpretación de los orígenes populares o folclóricos de la brujería obedece a esta exigencia.

Una interpretación racionalista de la brujería europea mantenía que ésta en realidad no existió, sino que había sido una creación irracional y dogmática de la religión oficial que sometía toda diferencia al sistema de sus imaginarias reglas divinas. En cuanto al papel que reservaba a los acusados, esta lectura los dejaba en las sombras del delirio fanático de la religión. Otra interpretación, que se subtendía en un desprecio nada velado por los campesinos y los analfabetos, pero que era una variante de la anterior, sostenía que las supuestas brujas fueron (como los judíos) chivos expiatorios de tensiones sociales. El temor de los campesinos a los brujos era producto, según $\mathrm{H}$. Trevor-Roper, de las "ideas absurdas, nacidas de la credulidad campesina y de la histeria femenina". Diferente era la explicación que ofrecía N. Cohn aludiendo a la existencia de un estereotipo hostil que el aquelarre corporizaría. El mismo aparecería en diversos grupos odiados, como los árabes, los judíos, los leprosos, las brujas, etc.

Los benandanti eran campesinos que, nacidos con el amnio, decian (o les era dicho) poseer ciertos atributos que realizaban durante los jueves de los cambios de estación. Salían en estado de "espíritus", llamados por una fuerza a la que no podían resistir, y montados en animales (liebres, ratas, etc.) salian por la noche a luchar con brujos y brujas. Los benandanti se reunian a luchar armados con haces de hinojo, mientras que los brujos y brujas se servían de ramas de sorgo para batallar. Estas luchas se hacían en nombre de dios, ciertamente, pues para los aldeanos que declaraban ante los tribunales ser benandanti, ellos peleaban contra los brujos enviados por el demonio. Pero había algo más. La lucha era importante porque se realizaba en los cambios de estación, y el resultado decidía si la cosecha próxima iba a ser exitosa o si, por el contrario, sería un fracaso. Por esa indicación Ginzburg traza la hipótesis que la creencia en los benandanti se vinculaba a los ritos de fertilidad en comunidades campesinas donde una mala cosecha significaba hambre y muerte.

Dos elementos coexistirian en esas creencias. Por una parte un estrato de significados más específicamente campesinos, donde los "espiritus" de ciertos individuos jugarían las esperanzas de un mejor pasar, y la representación de dios. Para los religiosos que interrogaban a los campesinos las informaciones recabadas les eran profundamente extrañas. Si recordamos que el primer caso data de 1575 viene a la memoria el contexto de la Contrarreforma que ajustaba cada expresión heterodoxa a los estereotipos prohibidos por la Iglesia.

Tratándose de reuniones nocturnas, donde se iba al encuentro con brujos y brujas -a pesar de que se decía hacerlo "en espíritu", en nombre de dios, y para combatirlos- los religiosos no hicieron sino encuadrar esas "reuniones" en el aquelarre. Es que se trataba de dos series discursivas radicalmente heterogéneas. Existian algunas indicaciones ambiguas en los bienaventurados, como su capacidad supuesta para deshechizar a los niños. Es claro que los testimonios aportados por los acusados no mencionaban los componentes habituales esperados en los aquelarres: abjuración de la fe, adoración y pacto con el demonio, orgías sexuales, muerte e ingestión de recién nacidos, etc. Las discusiones y repreguntas, las incoherencias y abiertas disputas sobre lo dicho y sus contenidos muestran, para Ginzburg, el esfuerzo por parte de los jueces e interrogadores eclesiásticos para adecuar los relatos de las salidas nocturnas a sus esquemas preconcebidos. En ocasión de uno de los tantos procesos, Ginzburg señala que "l'inquisitore vuole ad ogni costo far aderire le confessioni del benandante al modello de cui dispone -il sabba" ${ }^{(3)}$ Si la aceptación de esa conexión se 
irá imponiendo poco a poco en los propios acusados gracias a la presión de los inquisidores, el núcleo de creencias le parece al historiador italiano originario de convicciones campesinas antiquisimas y extendidas. Otros elementos de los viajes nocturnos, como la visión de muertos o la reunión con una diosa de la fertilidad agraria, establecen posibles vínculos de los benandanti con creencias más amplias, que entonces a modo de simple hipótesis no desarrollada Ginzburg alude como similares a algunos cultos chamánicos. ${ }^{(4)}$

No es posible para Ginzburg concebir aquí una relación paternal entre la cultura popular y la letrada. Se trata más bien de una disputa y una incomprensión mutuas. La segunda, naturalmente, dispone de medios de coerción y educación que harán que, hacia 1620, los acusados de ser benandanti comiencen a reconocer en sus salidas nocturnas la reunión con el diablo y otras características del aquelarre. ${ }^{(5)}$ Sin embargo, esa misma peculiaridad cultural campesina muestra que no se trata de concebir la cultura en el modelo durkheimiano de la "mentalidad colectiva".

Una gran deuda reconoce Ginzburg para elaborar una alternativa a estos intentos que se le hacen insatisfactorios, al trabajo de Mijail Bajtin. Brevemente expresado, para el autor ruso, en la cultura de la temprana modernidad europea se produjo una acción recíproca entre las culturas de las clases subalternas y las de las clases dominantes. Esa confluencia que también era un conflicto la hallaba en los escritos de híbridos culturales. François Rabelais sería para Bajtin su mejor mediador con su Gargantía y Pantagruel. Ginzburg no modificará en su estudio sobre el molinero friulano Menocchio nada del supuesto más general del enfoque de Bajtin, sino que se atareará en una estrategia más directa de acceso a ese intercambio entre la cultura popular y la cultura dominante.

En los dichos del molinero tratado en El queso y los gusanos, Ginzburg cree encontrar una muestra representativa de la cultura popular. Desde luego, Menocchio, por su lugar en la comunidad aldeana de Montereale (relativamente holgada) y su capacidad de lectura, no era ni mucho menos un tipo promedio, como el requerido por los análisis cuantitativistas. $\mathrm{El}$ argumento del historiador es que por su diferencia con sus vecinos, pero fundamentalmente con los inquisidores que lo interrogan, Menocchio presenta con relativa claridad un sustrato cultural que en otras condiciones sería invisible o demasiado elusivo.

La idea de la circularidad en los contactos entre las culturas popular y docta es una marca general de toda la obra de Ginzburg. No otro proceso se muestra en los interrogatorios que desde los años 1580 sufrirá Menocchio. Luego de treinta años de enseñar a sus vecinos sus creaciones teológicas, el molinero fue denunciado por el cura del pueblo. En los trabajos de inquisición el acusado mostraba un escaso respeto por las jerarquías eclesiásticas. ${ }^{(6)}$ Se entendía ese desprecio en el marco de la queja del molinero sobre los abusos de los ricos contra los pobres; los religiosos pertenecían en general al conjunto de los pudientes y no se abstenían de tales tropelías. Pero lo que más había sorprendido la compostura de los inquisidores era una excepcional cosmogonía que Menocchio decía haber elaborado sólo con su cerebro. En la mezcolanza de temas comprometidos en la peculiar cosmogonía solamente algunos son debidos a las lecturas que Menocchio reveló haber realizado. La inusual gama de textos no deriva necesariamente en una creación tan extraña. En el conjunto de sus creencias, la crítica a los ricos y a los clérigos puede comprenderse, ciertamente, en el marco de los grhpos reformistas, pero esta es una posibilidad que a Ginzburg no convence. En cambio, insiste en que la grilla de lectura e interpretación (que es también y muy especialmente una deformación) estaba dada por un fondo de cultura campesina, transmitida oralmente, donde predominaba un materialismo elemental, marcado por las experiencias de vida de los campesinos que debian luchar con la naturaleza y con 
otras fuerzas hostiles. ${ }^{(7)}$ Ese materialismo se imbricaba en Menocchio con una religiosidad práctica en la cual era más importante amar a los prójimos que a dios. Se producía, dice Ginzburg, una transición incompleta pero visible de un discurso religioso a otro moral. En ese campo, Menocchio cruzaba con sus invenciones una esperanza de transformación del mundo, una eliminación de las injusticias que notaba. La religiosidad práctica era al mismo tiempo, pues, una utopía de la transformación radical del mundo.

Ninguna contradicción en su pensamiento anularía el hecho decisivo de la creatividad del molinero. Existía una distancia notable entre las obras que dijo haber leído y sus interpretaciones de las mismas. Hemos ya sostenido que Ginzburg atribuye esa discrepancia en un sustrato de cultura popular que en Menocchio funcionaba como grilla de lectura. En otros términos, se trataba del contraste entre la cultura escrita y la cultura oral. Este fondo que probablemente databa de siglos y aun de milenios mostraba cierta permeabilidad a la cultura de las clases dominantes. El ejemplo del molinero friulano mostraba que en él la cultura popular materialista "convergía con refinadas teorizaciones religiosas de sus coetáneos". ${ }^{(8)}$ Por otra parte, la dinámica de ese encuentro no establecía una subordinación a la tradición oral bajo la escrita, pues nada aseguraba que la "racionalidad" de la cultura dominante fuera argumentativamente superior. De hecho, Menocchio se plantaba con confianza frente a los inquisidores, confiado en la potencia de su pensamiento. Su cosmogonía era, en cierto modo, señala Ginzburg, más cercana a las teorías "científicas" que pronto se iban a imponer con explicaciones que prescindían de la creación divina. El mundo aparecido del caos, junto a dios y los ángeles, se asemejaba mejor a los esbozos de una teoría de la generación espontánea que a los dogmas de la religión oficial. Es de notar que no consiste El queso y los gusanos en una investigación sobre un individuo. Por el contrario tal individuo es un síntoma de procesos más amplios y abarcadores que, por otra parte, serían incomprensibles sin la apelación a un contexto. Sin la Reforma y la Contrarreforma, que instituyen una Inquisición poderosa, sin la invención de la imprenta que extendió el número de lectores e hizo los libros más accesibles para quienes se preocuparan de conseguirlos, sin la lucha de clases que exacerbó las rebeliones campesinas de 1511 y en otro orden el aumento de los cánones que empeoraba la condición de los campesinos y facilitaba la reemergencia de utopismo y materialismo expresados por Menocchio, no se comprenderían los sucesos analizados detalladamente. Se ha criticado la falta de atención de Ginzburg respecto a las tensiones internas a la comunidad campesina. ${ }^{(9)} \mathrm{Y}$ aunque discuta el lugar social de los molineros, como en el caso de los benandanti hay que admitir que el tratamiento es por demás breve y descriptivo. Confirma esta limitación el énfasis menor de las investigaciones de Ginzburg en la historia social, siendo en cambio más proclive a las preguntas de una historia cultural que en una medida más aguda preocupan a Giovanni Levi o a Maurizio Gribaudi.

La preocupación por ese estrato de cultura popular milenaria a la que había aludido oblicuamente en las obras anteriores, es abordada directamente en el último libro histórico de Ginzburg. En efecto, Historia nocturna es un vertiginoso viaje a través del tiempo y del espacio para hallar, como en $I$ benandanti, las raices populares (ahora más precisamente folklóricas) de la brujería y la herejia. Si el tema es básicamente el mismo que en textos anteriores (pues a la principal de la persecución a las/os brujas/os se agregan reacciones contra nuevos miedos), los supuestos y métodos son muy distintos.

Entre otros acontecimientos, en 1321 se produjo una exterminación de leprosos en Francia. Las informaciones que han sobrevivido al tiempo indican diversas explicaciones, de las cuales las derivadas en castigos a conjuras anticristianas de los leprosos, judíos y musul- 
manes no faltaban. Si Ginzburg indica que las autoridades y algunos sectores de los burgos estaban interesados en inculpar a los judios a quienes les gustaría expropiar o expulsar, también nota que las persecuciones que luego fueron desatadas contra aquéllos encontraban un patrón común con la de los leprosos en que ambos grupos estaban relegados a los márgenes de la sociedad. El concilio lateranense de 1215 había prescrito que los judíos portaran en sus ropas un círculo amarillo, rojo o verde como un estigma. ${ }^{(10)}$ Ysi los hebreos habían logrado en la dinámica de ascenso de las ciudades mercantiles un bienestar económico, en el imaginario popular la percepción de su marginalidad persistía. Los ataques, sin embargo, indicaban claramente la intervención de las autoridades, entre las cuales estaban los representantes del poder divino. La fragua de documentos que probaban la conspiración de árabes, leprosos y judios para envenenar las fuentes y pozos de agua de los cristianos y apoderarse de sus tierras y riquezas es clara. Sin embargo, Ginzburg encuentra una confluencia de la creación voluntaria del mito de la conspiración con una predisposición popular a perseguir a quienes estaban en posiciones marginales. No se trataba, pues, de una maquinación desde arriba, sino que ella entroncaba con un miedo ampliamente sentido. Para el estudio de la convergencia de los dos procesos, que anulan todo intento de explicar las persecuciones por un complot tramado desde arriba, idea que se repite en diversos momentos y lugares, lo que posibilita pensar en una familiaridad entre las diversas violencias así justificadas. Ahora bien, ese sustrato profundo es el auténtico problema que Historia nocturna busca investigar, es decir, los posibles lazos invisibles que unen los mitos y creencias populares de persecuciones, reuniones nocturnas, cabalgatas en animales, retorno de muertos en procesión, luchadores contra brujos, hadas, persecuciones contra leprosos y judíos, aquelarres, cuentos campesinos y cortesanos, pertenecientes a tradiciones célticas, chinas, cretenses, helénicas, eslavas, germánicas, indias, etc.

No existe la posibilidad de probar documentalmente y en series de derivaciones históricas, todos los hilos y quiebres que unen y separan estos hechos y procesos históricos. Ciertamente, Ginzburg no arguye sobre la innecesariedad de una consideración de las precedencias cronológicas y los sentidos de las influencias y herencias. Por el contrario, lo que hay que explicar es por qué las persecuciones del trescíentos derivaron en una comprensión específica del aquelarre. La existencia de un fondo común de creencias no explica esta acontecimientalidad. Ginzburg prefiere jugar a una estrategia asintótica que atienda a la evidencia estructural, formal, y a la evidencia histórica, concreta.

No es tal aclaración una objeción contra la constatación de que es la estrategia estructural la más evidente y efectiva de Historia nocturna. Pero esta operación no es una de las tan corrientes permitidas por el eclecticismo. El uso, "crítico", del instrumental teórico de la antropología estructural que hace Ginzburg, especialmente de las obras de LeviStrauss, posee sus inconvenientes. La preocupación del historiador por la voz de los acusados en una perspectiva estructural se pierde necesariamente. Desde luego, las preguntas que conciernen a materiales -muchos de ellos arqueológicos e iconográficos- de épocas muy remotas imponen restricciones al intento de oír las voces propias de los perseguidos. Lna razón más decisiva, sin embargo, obliga al abandono de recuperar esas voces. Y es una obligación teórica de toda perspectiva estructuralista, a saber, la que deriva de la afirmación de la base inconsciente de los mitos y creencias.

Ginzburg, empero, no es totalmente fiel en este punto a Levi-Strauss, y por buenos motivos. Las morfologías entre los mitos que el historiador sigue a través del tiempo parecen poseer rasgos efectivamente comunes. Mediante este procedimiento se lanzan hipótesis que de otro modo sería imposible siquiera articular. ¿Cuál es la relación entre las versiones del 
mito de Edipo y las de Cenicienta? La documentación no alcanza para sustentar una posibilidad de comprobarlo. ${ }^{(11)} \mathrm{El}$ gran inconveniente de Ginzburg es su pretensión de mantener al mismo tiempo la demanda de una justificación empirica y diacrónica de su hipótesis. Ese fondo de creencias míticas que se extenderían por casi todo el mundo debe validarse en los diversos mitos e imaginarios que aquejan y permiten vivir a los seres humanos. Aqui, precisamente aquí, emergen dos nuevas preguntas: la primera (que sólo será aludida para retomarla en la siguiente sección) es el criterio para reconocer los caracteres decisivos de la estructura (morfología) que establece la conexión (formal) entre mitos aparentemente disímiles; la segunda, si se quiere más "histórica", concierne a las posibles explicaciones sobre las razones empíricas que permitieron la extensión de esos caracteres mítico-formales.

A partir de los primeros grupos humanos de los que se poseen rastros de haber creído en mitos vinculados al contacto con el mundo de los muertos (el auténtico núcleo de las creencias que Ginzburg investiga), pastores nómadas de Asia central, se hace necesario explicar su presencia entre lapones, húngaros y celtas. Ginzburg maneja para ello tres explicaciones probables, a saber: a) difusión, es decir, la transmisión de las creencias (en la reencarnación de animales, el vuelo nocturno, por ejemplo) por contactos culturales o de otro tipo; b) derivación de una fuente común, que es en realidad una variante de la anterior; c) "derivación de características estructurales de la mente humana". (12)

Las dos primeras posibilidades, si bien encuentran para Ginzburg documentación que apoye ciertas explicaciones, son insuficientes. Para defender la pertinencia de la tercera opción, Ginzburg partió en busca de una condición común de la vida cultural, que abarca a todos los scres humanos. "Hace mucho tiempo", dice el historiador italiano con alguna imprecisión, "me propuse demostrar experimentalmente desde un punto de vista histórico. la inexistencia de la naturaleza humana; y hoy, veinticinco años más tarde, me veo sosteniendo una tesis exactamente contraria". (13) El propio autor es consciente de las implicancias de una historia sin sujetos. "En el estudio de los hechos humanos, poniendo entre paréntesis la dimensión temporal se obtiene un cuadro inevitablemente deformado, por estar depurado de las relaciones de fuerza. La historia humana no se desarrolla en el mundo de las ideas, sino en el mundo sublunar en el que irreversiblemente nacen los individuos, infligen sufrimiento o lo padecen y mueren... Así pues, me parecía que la investigación morfológica no podía (por motivos a la vez intelectuales y morales) sustituir a la reconstrucción histórica" (14) Sin embargo, debemos señalar que tales suposiciones se llevan mejor con I benandanti o El queso y los gusanos que con la más tardía Historia nocturna.

\section{Consideraciones sobre ciencia y método}

Luego de haber abordado las cuestiones referidas al "contenido" de la ontología histórica propuesta por Carlo Ginzburg podemos intentar explicitar sus convicciones respecto a la historia como disciplina con aspiraciones científicas. En una elaboración ya avanzada en su trayectoria historiadora, Ginzburg intentaba argumentar por un renovado paradigma de conocimiento, en muchos aspectos radicalmente diferente de la racionalidad fisico-matemática (o galileana) que dominó las ciencias occidentales por lo menos desde el siglo XVI. ${ }^{(15)}$ Más exactamente, el paradigma recuperado, sería una emergencia de un saber antiquísimo, producido en condiciones muy diversas a las del paradigma galileano. Una primera consta- 
tación teórica a sostener es que marcar esa alteridad de producción de conocimiento respecto a una racionalidad que se creía universal y eterna, historiza de ésta sus pretensiones de validez absoluta, y por ende la destruye en tanto que razón monológica. Pero Ginzburg señala que su indagación sobre este antiguo paradigma "indiciario" pretende aportar ayudas para salvar el tembladeral de la contraposición entre "racionalismo" e "irracionalismo".

La cualidad primera y definitiva del paradigma de los indicios, como su nombre lo denuncia, es la atención prestada a los detalles, en evidente contraposición al saber galileano, que necesita de la regularidad y la homogeneidad como precondiciones para apelar a leyes y predicciones. La formación médica de quienes reactualizaron el paradigma indiciario (según Ginzburg, G. Morelli, S. Freud y A. Conan Doyle) habría facilitado la percepción particular de un modo de conocimiento irreductible a leyes. La medicina habría conservado marcas, ya viejas, de una carencia: la de poder identificar plenamente sus objetos de estudio. No existen enfermedades, sino que hay enfermos. Este modo de conocer tiene una larga historia, que Ginzburg construye aludiendo a los primitivos cazadores, pasando a los tiempos de las primeras civilizaciones mesopotámicas, para transitar por el medioevo hasta el nacimiento del psicoanálisis. De acuerdo al autor, el inicio práctico de este saber, que habría sido el primero en surgir, se produjo cuando los seres humanos aprendieron los rudimentos de la caza y persecución de animales, actividad para la que era imprescindible la identificación de los rastros dejados por las presas potenciales. De esas huellas los cazadores primitivos obtendrían informaciones del tipo y tamaño de animal buscado, de la dirección de su andar, etc.

Entre las antiguas aplicaciones del tipo de conocimiento indiciario se mezclan, inopinadamente, algunos saberes con pretensión de rigurosidad - como la fisiognómica, el derecho (jurisprudencia) y la medicina- junto a otros que se vinculan a lo esotérico - como la adivinación-. Sin embargo, estas distinciones no son relevantes para la configuración del paradigma, pues en todos los casos se trata de puestas en práctica de inferencias sintomatológicas destinadas a descubrir una realidad (corporal, sentimental, delictiva, etc.) que está conectada metonímicamente con las senales analizadas. Los procederes, que como las experiencias extáticas o estimuladas por alucinógenos, no pertenecen a este tipo de saberes pues allí se excluye el razonamiento lúcido, imprescindible para establecer las inferencias.

Habría que cuidarse, empero, de ubicar al paradigma indiciario en una grilla racionalista pura de análisis. "Se trata, dice Ginzburg, de formas del saber tendencialmente mudas -en el sentido de que, como ya dijimos, sus reglas no se prestan a ser formalizadas, y ni siquiera expresadas-. Nadie aprende el oficio de connoiseur o el de diagnosticador si se limita a poner en práctica reglas preexistentes. En este tipo de conocimiento entran en juego (se dice habitualmente) elementos imponderables: olfato, golpe de vista, intuición".(16)

La conexión entre medicina e historia no es solamente accidental. Años más tarde de la publicación del texto Indicios, Ginzburg reforzará la idea de la comunión entre ambas disciplinas mostrando, o mejor explicitando, que la historia se conformó en tanto saber como género y como actividad intelectual, haciendo confluir la medicina y la retórica, con esa búsqueda de una causa "natural" y la fundamentación propia del arte de disuadir en los tribunales. ${ }^{(17)}$ Una combinación inquietante, desbarrancada en la lucha interpretativa y la irreductibilidad.

En cualesquiera de los libros mencionados en la primera parte del presente texto funciona, tal como Ginzburg parece buscarlo, una especial atención a los matices que 
contienen los documentos, que dicen sin querer y muestran marcas de silencios. El valor testimonial de las fuentes históricas, muy a pesar de la indudable deformación de cualquier referencia positivista, es una verdad defendible. En los quiebres y desniveles de los textos o en las ambigũedades de las imágenes se encuentran núcleos de significados donde puede residir la clave de toda una trama histórica. Por una parte, los documentos son fragmentarios, son recortes imperfectos, crudos y ariscos. Las/os historiadoras/es intentan inferir los tramos oscuros y faltantes, apoyándose en múltiples marcas alternativas, y esa operación soporta un pecado: toda reconstrucción que acuse una amplia cuota de imaginación histórica contextualmente fundamentada la hace necesariamente refutable. El saber así elaborado es una posibilidad y no un seguro reflejo (que solamente puede plantearse desde el punto de vista de dios). ${ }^{(18)}$

Además de una falta material de abundante documentación, en Ginzburg es importante otra prevención: las fuentes son un resultado de la relación de fuerzas entre las clases. ${ }^{(19)}$ Quienes han escrito, digamos, las actas de los juicios inquisitoriales o de los interrogatorios a los leprosos franceses, fueron sus perseguidores. En el caso del campesinado y otras clases subalternas donde la cultura oral es el medio donde se piensa y se actúa, y las indicaciones sobre ella solamente son accesibles en épocas pasadas a través de la escritura de las clases dominantes y sus letrados. La limitación a las fuentes "oficiales" conlleva casi siempre escuchar sólo las gargantas y plumas "oficiales". Pero esa búsqueda no es nada fácil. En general se necesita exprimir los documentos que, desde otras ópticas, serían de importancia marginal. "Las voces de los acusados", escribe Ginzburg, "nos llegan sofocadas, alteradas, distorsionadas; en muchos casos no concuerdan. De aquí - para quien no se conforme con escribir por enésima vez la historia desde el punto de vista de los vencedores- la importancia de las anomalías, de las grietas que se abren en ocasiones (muy raramente) en la documentación, hendiendo su compacidad". ${ }^{(20)}$ La lectura atenta a las peculiaridades de esas "voces" aproxima a la microhistoria de Ginzburg (aun en sus momentos menos micro) a una tarea etnográfica.

La recurrencia a fuentes más polisémicas de lo acostumbrado o la busca de significados reprimidos, lo hemos visto en la discusión sobre el paradigma indiciario, recababa información en los detalles. Pero esos detalles pueden someterse a debate en su validez. En una entrevista se le pregunta, muy perspicazmente, por la necesidad que tal indagación supone de modificar los estándares de prueba aceptados. $\mathrm{Y}$ es una pregunta pertinente porque la deconstrucción de una fuente reclama atender, en una lectura sintomática, a los silencios y deslices, que como en el caso de Freud, son discutibles. Mucho más lo es en el tipo de rescate que Ginzburg intenta. Está claro que en términos de una cultura de historia académica empirista las "pruebas" aportadas por Ginzburg en algunas de sus obras son insuficientes. Lo que debe notarse es que esa supuesta debilidad se hace una y la misma cuestión con su proyecto de salvar a los vencidos, para utilizar las palabras de Thompson, "de la enorme condescendencia de la posteridad". Ahora bien, la cuestión no se sutura con una declaración ético-política de este tenor. Y no sucede ello porque se trata de una naturaleza muy distinta: concierne a los créditos método-epistemológicos de una disciplina con aspiraciones científicas.

Un objeto de investigación para Ginzburg implica ciertas condiciones en el análisis de los documentos y afecta al carácter del "conocimiento" elaborado. Desde luego, esta concatenación puede darse de diversos modos, algunos de los cuales puede deber más a la reproducción institucional de la disciplina histórica que a intereses de conocimiento que acepten otras demandas. Lo interesante de la situación de Ginzburg es que no deriva en un 
populismo relativista, sino que argumenta por una limitada pero efectiva pretensión de verdad. ¿De qué otro modo se entendería su proyecto de "rescate" de las víctimas? ${ }^{(21)}$

Se comprende en este contexto el alejamiento que Ginzburg remarca respecto al relativismo absoluto del postmodernismo. Ante intentos de la inclusión de sus textos entre una supuesta nueva historia narrativista, el historiador no podría reaccionar sino con perplejidad, puesto que no solamente una apelación a la "totalidad" se encontraba en la propia discusión sobre las huellas, ${ }^{(22)}$ sino que en repetidas oportunidades ha valorado los aportes de la microstoria por su contribución a la comprensión de los grandes procesos sin eliminar los márgenes para la acción humana.

Hemos visto que la argumentación de Historia nocturna es muy distinta a la de textos anteriores. Es necesario plantear algunos interrogantes al respecto. ${ }^{(24)} \mathrm{La}$ identificación de ciertos rasgos morfológicos en los mitos antiguos le permite a Ginzburg, siguiendo la idea de Wittgenstein, encontrar ciertos parecidos de familia en relatos e imágenes muy diferentes en cuanto a su contenido. Para ello elude la clasificación monotética, que ordena las clases bajo la supremacia de un atributo definitorio, para acudir a la apertura de esa esquemática en la clasificación politética que teoriza el antropólogo británico Needham. Mientras en la clasificación monotética, que por ejemplo establece la clase "mujeres" por la posesión de un conjunto de atributos bio-fisiológicos, o la clase "proletariado" por la carencia de medios de producción como propiedad, la clasificación politética renuncia a buscar ese atributo decisivo para clasificar a través de combinaciones diversas de una multiplicidad de atributos. Para Ginzburg, es lícito establecer una conexión entre dos mitos porque a pesar de que no compartan cualidades de contenido sí es posible establecer que alguno de los diversos atributos que los estructuran tenga un "parecido de familia". La pregunta fundamental es qué criterio puede aducirse para reconocer algunos atributos que alcanzan la categoría de "parecido de familia" para justificar la proximidad, por ejemplo, entre mitos y ritos tan diferentes. ¿Por qué los dos mencionados por Ginzburg y no otros, que quizás marcarian la alteridad radical entre chamanes y benandanti? ¿No subyace aquí una adopción acrítica de esa propiedad del paradigma indiciario cuyas reglas se confunden con la adivinación y no pueden siquiera ser dichas?

La propuesta de Ginzburg es otra. Indudablemente la estrategia seguida en Historia nocturna puede ser discutida y el historiador italiano no rehuye el debate sobre la firmeza o debilidad de su base empírica. Por el contrario, la apelación a ese instrumento es el núcleo de la defensa de la pretensión de verdad de la historia. Ginzburg ha discutido repetidamente las teorias relativistas absolutas como las de Hayden White, que considera, además de erróneas, éticamente deleznables. ${ }^{(25)}$

Con cierta displicencia Ginzburg indica que su postura conjuga una predisposición por una noción positivista (debiera decir "realista") de la verdad y una antipatia por cualquier ingenuidad positivista sobre el conocimiento. Para él, la "mayor conciencia de la dimensión narrativa no implica una atenuación de las posibilidades cognoscitivas de la historiografía sino al contrario su intensificación". ${ }^{(26)}$ Este razonamiento se sigue asi: la falibilidad del conocimiento, que debe lidiar con la ideología que aqueja toda producción de saber ${ }^{(27)}$ (en tanto práctica) y con las dificultades impuestas por la documentación, junto a la percepción de la especificidad constructiva de la narración, exacerban los recaudos de los/as historiadores/as para utilizar conceptos y realizar inferencias. Si a veces se podria exigir a Ginzburg que se tomara más a pecho esta última consecuencia, lo cierto es que su perspectiva teórica lo aleja de todo escepticismo epistemológico. Lo que más manifiestamente parece faltar en su argumentación es una crítica de la práctica historiadora en las condiciones del capitalis- 
mo avanzado, y de sus instituciones. Pero se perdería la especificidad de la intervención epistemológica de Ginzburg sin notar la fuerte impronta ético-política, una evidente militancia intelectual, que le otorga a su obra un sentido de apasionamiento singular.

\section{Notas}

(1) Cf. Carlo Ginzburg, I benandanti. Stregoneria e culli agrari tra Cinquecento e Seicento, Turín, Einaudi, 1994 [1966].

(2) Cf. Carlo Ginzburg, Histomia nocturna, Barcelona, Muchnik, 1991.

(3) Cf. Carlo Ginzburg, I benandanti, op. cit., pág. 18.

(4) Idem, págs. XIII-XIV, 88-90.

(5) Véase, más en general, Carlo Ginzburg, "Folklore, magia, religione", en: Storia d'ttalia, vol. I. Turín, Einaudi, 1972, especialmente págs. 649-650.

(6) Cf. Carlo Ginzburg, El queso y los gusanos. Barcelona, Muchnik, 1991 [1976], pág. 36.

(7) Idem, págs. 76, 106, 131, 137.

(8) Idem, pág. 93.

(9) Cf. E. Grendi, "Repensar la microhistoria", en: Entrepasados, Ne 10, Buenos Aires, 1996; y Keith Luria, "The paradoxical Carlo Ginzburg", en: Rudical Histomy Revievu, N 35, 1986, pág. 83.

(10) Cf. Carlo Ginzburg, Historia norluma, op. cit., pág. 46.

(11) Algún crítico inmisericorde traería aquí a colación que Ginzburg reconoce que su hipótesis respecto a la confluencia entre la cultura oral y la escrita en Menocchio era "indemostrable". Cf. El queso y los gusanos, op. cit., pág. 184.

(12) Cf. Carlo Ginzburg, Historia nocturna, op. cit., pág. 167.

(13) Idem, pág. 33.

(14) Idem, pág. 27. Nuevas consideraciones, en las cuales aqui no podemos entrar fueron publicadas por Ginzburg recientemente en Occhiacti di legna, nove niflessioni sulla distanzu, Turin, Einaudi, 1998.

(15) Cf. Carlo Ginzburg, "Indicios. Raíces de un paradigma de inferencias indiciales", (1979), en: Milos, emblemas, indictios. Morfologiza e historin, Barcelona, Gedisa, 1989, pág. 138.

(16) Cf. Carlo Ginzburg, "Indicios. Raíces de un paradigma de inferencias indiciales", op. cit., pág. 163.

(17) Cf. Carlo Ginzburg, El juez y el historiador. Consideraciones al margen del proceso Sofri, Madrid, Anaya-Muchnik, 1993, pág. 18.

(18) Cf. Carlo Ginzburg, "Pruebas y posibilidades. En los márgenes de El retorno de Martin Guerre", postfacio a Natalie Zemon Davis, Il Rilumo di Martin Cuemre. Un raso di doppia identitì nellit Francia del cinquecento, Turín, Einaudi, 1984, publicado por la ed. Biblos, Buenos Aires, 1989.

(19) Cf. Carlo Ginzburg, El queso y los gusanos, op. cit., págs. 184, 232.

(20) Cf. Carlo Ginzburg, Historia nocturna, op. cit., pág. 21.

(21) Una importante discusión teórica puede aqui ser solamente esbozada: la idea de una reconstitución histórica de las subjetividades y experiencias de personas y clases del pasado es una operación demasiado ambiciosa, pero para muchos/as necesaria. Pero eno muestra ello una intención de "estar en la piel" de otros radicalmente otros? ¿no oculta una violación de la peculiaridad inaferrable de las víctimas con la falsa o ingenua aspiración a una recuperación exenta de una voluntad de poder existente como mala fe? Ginzburg ha reconocido la necesidad de aceptar un margen de indescifrabilidad de las experiencias y deseos (cf. El queso y les gusananos, op. cit., págs. 25, 28; "Carlo Ginzburg: an interview", en: Radical History Review, número citado, pág. 106.

(22) Cf. Carlo Ginzburg, "Indicios", op. cit., pág. 162.

(23) Cf. Lawrence Stone, "The Revival of Narrative: Reflections on a New Old History", en: Past und Present, $\mathrm{N}^{2}$ 85, 1979; F. R. Ankersmit, "Historiography and Postmodernism", en: History and Theomy, vol. 28, № 2 , 1989. 
(24) Sobre este punto no haremos sino desarrollar brevemente algunas ideas de la devastadora reseña crítica de Perry Anderson, "Pesquisa nocturna: Carlo Ginzburg", en: Secuencia. Revista de historia y ciencius sociales, $\mathrm{N}^{2} 29,1994$, págs. 191-216, a la que remitimos.

(25) Cf. Hayden White, Metahistoria. México, Fondo de Cultura Económica, 1987; y El contenido de la forma. Narrativa, discurso y representución histónica, Barcelona, Paidós, 1992. Ginzburg discute específicamente los trabajos de White en: "Just One Witness", en: Saul Friedländer (ed.), Proling the limils of representation. Nazism and the "Final Solution", Cambridge, C.U. Press, 1994, págs. 82-96.

(26) Cf. Carlo Ginzburg, "Pruebas y posibilidades", op. cit., pág. 15.

(27) Cf. Carlo Ginzburg y Adriano Prosperi, Giochi di pazienzu. Un seminario sul "Beneficio di Cristo", Turín, Einaudi, 1975 , págs. 178 y ss. 